\title{
EVIDÊNCIAS DE CICLOS POLÍTICOS NO SENADO FEDERAL ${ }^{1}$
}

\section{EVIDENCE OF POLITICAL CYCLES IN THE FEDERAL SENATE}

\author{
César Leonardo dos Santos \\ Graduando em Ciências Contábeis (FURG) \\ cesarleonardo11c11@gmail.com \\ Vagner Horz \\ Doutorando em Ciências Contábeis (UFU) \\ vagnerhorz@gmail.com \\ Anderson Betti Frare \\ Doutorando em Ciências Contábeis (UFSC) \\ anderson betti frare@hotmail.com \\ Alexandre Costa Quintana \\ Doutor em Ciências Contábeis (USP) \\ Universidade Federal do Rio Grande (FURG) \\ professorquintana@hotmail.com \\ Rodrigo Nobre Fernandez \\ Doutor em Economia (UFRGS) \\ Universidade Federal de Pelotas (UFPEL) \\ rodrigo.fernandez@ufpel.edu.br
}

\section{RESUMO}

Objetivo: Analisar se há diferenças significativas nos gastos públicos dos Senadores entre o primeiro e último ano de mandato.

Fundamento: Teoria dos Ciclos Políticos como elemento para analisar a influência do Mandato Eleitoral sobre os Gastos Públicos.

Método: O estudo se caracteriza como descritivo, com abordagem quantitativa do problema. A amostra foi composta por 78 senadores, dividida em dois grupos: mandato um são os senadores da legislatura 2011-2018, 2/3 do total (52), e o mandato dois são os da legislatura 2015-2022, 1/3 do total (26). Foram realizadas Análises Descritivas, Correlações de Pearson e Parciais, Teste de Levene e Teste da estatística T para duas amostras independentes (Teste de Médias).

Resultados: Observa-se que a maior parte dos gastos públicos analisados não demonstra diferença significativa em relação ao mandato em que os senadores estão exercendo. Apesar dos senadores que exercem o primeiro mandato apresentarem maior média de gastos, para aluguel e serviços,

\footnotetext{
${ }^{1}$ Artigo recebido em: 02/03/2020. Revisado por pares em: 27/08/2020. Reformulado em: 13/05/2020. Recomendado para publicação: 29/08/2020 por Lidiane Nazaré da Silva Dias (Editora Adjunta). Publicado em: 07/09/2020. Organização responsável pelo periódico: UFPB
} 
estes dois gastos são significativamente maiores para os senadores que atuam no segundo mandato.

Contribuições: No âmbito de implicações teóricas, o estudo contribui com a literatura sobre ciclos políticos, abarcando os gastos públicos com senadores brasileiros, em específico ao analisar a diferença de gastos em relação aos senadores que estão no primeiro ou segundo mandato. Sob a ótica de implicações práticas, a pesquisa espera instigar o acompanhamento social da aplicação dos recursos públicos, em especial aos gastos executados por políticos e em específico, dos senadores, além do direito do cidadão ao acompanhamento da destinação de recursos públicos.

Palavras-Chave: Ciclos Políticos. Senado Federal. Gastos Públicos.

\section{ABSTRACT}

Objective: Analyze whether there are significant differences in Senators' public spending between the first and last year of their term.

Background: Theory of Political Cycles as an element to analyze the influence of the Electoral Mandate on Public Spending.

Method: The study is characterized as descriptive, with a quantitative approach to the problem.

The sample was composed of 78 senators, divided into two groups: mandate one is the senators of the 2011-2018 legislature, 2/3 of the total (52), and mandate two are those of the 2015-2022 legislature, $1 / 3$ of the total (26). Descriptive Analyzes, Pearson and Partial Correlations, Levene's Test and T-statistic test were performed for two independent samples (Means Test).

Results: It is observed that most of the public spending analyzed does not show a significant difference in relation to the mandate in which the senators are exercising. Although the senators who exercise the first term have a higher average of expenses, for rent and services, these two expenses are significantly higher for senators who work in the second term.

Contributions: Within the scope of theoretical implications, the study contributes to the literature on political cycles, covering public spending on Brazilian senators, specifically by analyzing the difference in spending compared to senators who are in the first or second term. From the perspective of practical implications, the research hopes to instigate the social monitoring of the application of public resources, in particular to expenditures carried out by politicians and, in particular, senators, in addition to the citizen's right, to monitor the allocation of public resources.

Keywords: Political cycles. Federal Senate. Public spending.

\section{INTRODUÇÃO}

A Contabilidade Aplicada ao Setor Público está intimamente ligada à gestão do orçamento público e à transparência pública, portanto, as escolhas dos governantes voltadas à maximização da possibilidade de sua reeleição ou à de seus aliados também deverão ser refletidas nos registros e demonstrações contábeis (Vicente \& Nascimento, 2012). Desse modo, os eleitores avaliam o desempenho do partido que está no governo e utilizam a democracia para propagar suas preferências (Breder \& Drazen, 2013).

Neste ínterim, as pesquisas sobre ciclos políticos não fornecem respostas simples para a relação entre eleições e mudanças na política econômica e gastos públicos. Em vista disso, os resultados dependem de uma série de fatores, tais como o sistema eleitoral e governamental, a motivação dos candidatos e o processo de tomada de decisões governamentais (Breder \& Drazen, 2013).

Destarte, a presença e intensidade dos ciclos políticos-orçamentários são impulsionadas por contextos em que coexistem democracias com baixo nível de transparência e regras fiscais pouco 
rígidas. Dentre esses fatores capazes de determinar a existência e magnitude dos ciclos políticosorçamentários encontram-se os gastos públicos (Queiroz, 2018).

No processo eleitoral, o ano eleitoral compreende o momento oportuno para os gestores sinalizarem a competência e aumentarem as chances de recondução de seu grupo político ao poder. No âmbito brasileiro, diversas pesquisas (Bartoluzzio \& Anjos; 2020; Carvalho \& Oliveira, 2009; Nunes, 2017; Sakurai, 2005, 2009; Sakurai \& Menezes Filho, 2011; Queiroz, Araújo, De Morais, \& Da Silva, 2015; Queiroz, 2018; Veloso \& Bornhold, 2016) ratificam a influência do ano eleitoral sobre categorias específicas da despesa pública, como gastos de aluguel, aquisição, locomoção, contratação, divulgação, passagens, serviços, dentre outros. Os investimentos consistem no grupo que mais sofrem alterações nesse período, uma vez que maiores gastos com investimentos estão associados às maiores probabilidades de sucesso nas eleições (Queiroz et al., 2015; Vicente \& Nascimento, 2012).

O Senado Federal desfruta de uma ampla estrutura para servir ao seu funcionamento, apartamentos funcionais, residência oficial do Presidente da Casa, carros oficiais e escritórios de apoio de cada parlamentar em seu Estado de origem. Esse conjunto forma um custoso sistema de funcionamento do parlamento brasileiro. Cada senador custou aos cofres públicos brasileiros, em 2017, observados dados do Projeto de Lei Orçamentária Anual de 2017, cerca de R\$ 52,4 milhões, correspondendo a aproximadamente 54 mil salários mínimos (de acordo com o valor do salário mínimo de $\mathrm{R} \$ 954,00$, para o ano de 2018) (Neto, Gomes, \& Ervilha, 2018).

Diante desse contexto, em virtude da não localização de estudos pregressos que investiguem possíveis evidências de ciclos político-econômicos no Senado Federal Brasileiro a partir dos gastos públicos, elaborou-se o seguinte problema de pesquisa: Existem diferenças significativas nos gastos públicos dos Senadores entre o primeiro e último ano de mandato? $O$ trabalho tem por objetivo analisar se há diferenças estatisticamente significativas nos gastos públicos dos Senadores entre o primeiro e último ano de mandato. Espera-se que essa relação possa apresentar fatores que expliquem o comportamento dos gastos públicos efetuados pelos senadores brasileiros em atividade.

Justifica-se essa pesquisa em função de uma lacuna existente na literatura nacional ao não relacionar a composição dos gastos públicos com os resultados eleitorais, uma vez que as pesquisas brasileiras não têm abordado a influência do mandato sobre estes gastos dos senadores (Arvate, Mendes, \& Rocha, 2010; Klein, 2010; Nakaguma \& Bender, 2010; Queiroz et al., 2015; Queiroz, 2018).

Este trabalho pode estimular o acompanhamento social no que tange ao uso de recursos públicos. Despertar, em cada cidadão, o lume pela fiscalização e participação nos assuntos políticos e, do mesmo modo, fazer-se elucidativo o destino dos valores monetários para o distender das atividades dos senadores. Contribui, também, teoricamente, com a literatura dos ciclos políticos, com a evidenciação dos gastos públicos dos senadores em atividade no início de mandato e no fim de mandato (Shepsle, Van Houweling, Abrams \& Hanson, 2009; Queiroz et al., 2015; Queiroz, 2018; Sakurai \& Menezes-Filho, 2011).

Em suma, o texto encontra-se estruturado em cinco seções. Nesta primeira, introduz-se ao tema e as discussões relacionadas. Na sequência, aborda-se a revisão teórica acerca da teoria dos Ciclos Políticos e Gastos Públicos. Na terceira seção delimitam-se os métodos utilizados, seguido pela seção da análise e discussão dos dados, e, por último, as considerações finais, com as colocações acerca dos achados, limitações e sugestões.

\section{REVISÃO TEÓRICA}

A teoria dos ciclos políticos surge da necessidade de se investigar a forma em que as ideologias políticas e o comportamento dos gestores se organizam em função do calendário eleitoral. A 
relação entre a situação econômica e o calendário eleitoral foi estabelecida por Downs (1957), em que a função social de executar políticas públicas é realizada de acordo com o interesse particular do gestor público.

Com isso, as influências das manobras políticas sobre o comportamento da economia estão baseadas em possíveis manipulações das variáveis econômicas, com reflexos nas decisões eleitorais (Brender \& Drazen, 2013). Com base na teoria dos ciclos políticos, em época de eleição, os governantes podem implantar políticas públicas para manipular a economia, tendo como objetivo principal favorecer sua reeleição (Nordhaus, 1975).

A Political Budget Cycle (Ciclo Político Orçamentário) tem como pressuposto que o governo observa um indicador de desempenho antes dos eleitores (Rogoff, 1990). Desta forma, os gestores possuem o incentivo para distorcer a política fiscal no período que antecede as eleições, com o objetivo de sinalizar competência e aumentar suas chances de sucesso eleitoral (Queiroz, 2018). Os modelos cujas explicações são baseadas na política fiscal formam uma base com ampla solidez, no intuito de prover uma discussão convincente da influência das características eleitorais sobre os resultados econômicos (Drazen, 2001).

Tem-se ciência de que tanto o político que ocupa o cargo público quanto o seu adversário não eleito procuram vencer as eleições. Nesse sentido, o político governante tem a seu favor liberdade ilimitada de ação dentro das premissas da constituição, e poderá articular ações, valendo-se de influências governamentais para conseguir a reeleição (Downs, 1957).

A estrutura básica do governo racional está alicerçada na motivação para continuar no poder, segundo Downs (1957), os policy markers formulam políticas para ganhar as eleições e não ganham as eleições para formular políticas. A criação dos partidos políticos está vinculada a motivação pessoal, em especial aos que assumem cargos políticos.

As conexões entre as eleições e gastos como despesa total, corrente e investimento foram alvo da pesquisa de Sakurai \& Menezes-Filho (2008). No referido estudo, os resultados apontaram a existência de maiores gastos públicos no período do mandato de prefeitos brasileiros, assim obtendo maior probabilidade de reeleição dos mesmos. Desse modo, há modificações na composição do orçamento, aumentando-se o gasto público em itens mais visíveis, como serviços, e diminuindo-se o gasto com investimentos, cujos resultados exigem mais tempo para serem percebidos pelo eleitorado (Rogoff, 1990; Rogoff \& Sibert, 1988).

Além disso, a existência de informação incompleta proporciona ao político o incentivo de distorcer a política fiscal pré-eleitoral de forma a aumentar sua probabilidade de reeleição. Assim, os autores argumentam que os ciclos eleitorais observados em algumas variáveis de política macroeconômica (impostos, gastos governamentais, déficits e expansão monetária) derivam de assimetrias informacionais (Rogoff, 1990; Rogoff \& Sibert, 1988).

Logo, a teoria dos ciclos políticos liga a economia à população. No que concerne na elucidação de que a política é conduzida com enfoque nos interesses pessoais de nossos governantes e não pela busca do bem-estar social (Brender \& Drazen, 2005). Destarte, que a existência de ciclos políticos se atribui à falta de transparência, que pode ocorrer tanto em novas quanto em velhas democracias (Alt \& Lassen, 2006; Brender \& Drazen, 2005).

No que tange à influência do mandato eleitoral sobre os gastos públicos, estes últimos são conhecidos como despesas públicas, por sua vez, são os gastos dos recursos públicos nos orçamentos, a partir de autorização legislativa (Nascimento, 2006). Já conforme Araújo, Monteiro e Cavalcante (2010) os gastos públicos são todos os gastos governamentais, ou seja, despesas das unidades que compõem a administração direta e indireta, mais as despesas referentes às atividades econômicas produtivas.

Não obstante de definição semelhante, uma parte dos gastos públicos são destinados às demandas sociais, ou seja, aquelas que estão ligadas ao cotidiano das pessoas (Scarpin \& Slomski, 
2007). Nesta perspectiva, conforme Rezende (1997) os gastos sociais compreendem os valores aplicados nas funções orçamentárias.

Desse modo, no que se refere à constituição dos gastos públicos, os mesmos são compostos por elementos de despesa que tenham as mesmas características quanto ao objeto do gasto (Slomski, 2003). Assim, as despesas orçamentárias são participantes da Lei Orçamentária Anual - LOA (Silva, 2004). Logo, a despesa pública pode ser analisada sob duas óticas: patrimonial e orçamentária (Andrade, 2012). Pela ótica do enfoque patrimonial, as despesas representam um decréscimo do patrimônio líquido, que não seja resultante da distribuição para os proprietários da entidade, enquanto pelo enfoque orçamentário a despesa pode ou não diminuir a situação líquida patrimonial (Ferreira, 2016).

Contudo, existem vários fatores que afetam o nível dos gastos públicos (Araújo, Monteiro, \& Cavalcante, 2010). Dentre esses fatores observa-se a magnitude dos ciclos político-orçamentários, descrita pela literatura da Teoria dos Ciclos Políticos (Downs, 1957; Nordhaus, 1975). Desse modo, presume-se que os gestores aptos a concorrer à reeleição apresentam um volume mais elevado de gastos públicos (Queiroz, 2018).

Sakurai e Menezes (2008), após análise de 2.235 municípios entre 1988 e 2000, identificaram que os gestores que apresentaram gastos per capita mais elevados nos últimos anos de mandato tiveram mais chances de recondução no cargo. Por sua vez, Klein (2010) testou a presença de ciclos político-orçamentários nas eleições municipais do Brasil com uma amostra composta por 5.406 municípios na eleição de 2004. Os resultados evidenciaram que os prefeitos que adotam tal política possuem maior probabilidade de reeleição.

Essas resultados corroboram com outras pesquisas nacionais (Queiroz et al., 2015; Vicente \& Nascimento, 2012) e internacionais (Brender \& Drazen, 2013; Drazen \& Eslava, 2010; Veiga \& Veiga, 2007) que indicam que os governantes que aplicam mais recursos em investimentos de curto prazo apresentam maiores probabilidades de serem reeleitos.

A pesquisa de Klein e Sakurai (2015) propôs o mandato eleitoral como um fator determinante para a ocorrência dos ciclos político-orçamentários. Foram analisados 3.393 municípios brasileiros entre 2001 e 2008. Os resultados mostraram que os prefeitos que estão no primeiro mandato aumentaram as despesas públicas, especialmente os investimentos.

No estudo de Queiroz, Morais, De Souza, e Da Silva (2019) foi averiguada a influência do mandato eleitoral sobre os gastos públicos dos governos estaduais brasileiros, com amostra composta pelos 26 Estados brasileiros no período de 2003 a 2014. Os resultados mostraram que o comportamento oportunista é restrito aos governadores que estão em primeiro mandato na composição dos gastos públicos em direção aos investimentos nos períodos eleitorais. As pesquisas de Klein e Sakurai (2015) e Queiroz (2018) averiguam como o fator mandato eleitoral influencia a política fiscal de municípios e Estados, respectivamente.

Fiirst, Santos, Rodrigues Junior e Zonatto (2019) analisaram o efeito de características políticas no desempenho financeiro de municípios do Paraná. Os achados denotaram que o ano eleitoral influência positivamente no desempenho financeiro, mas que cuja relação se configura negativamente quando acontece a troca do gestor.

No estudo de Arvate, Mendes e Rocha (2010) foram investigadas as eleições em 2.732 municípios brasileiros no ano de 2000, para verificar se os eleitores preferem um comportamento fiscal conservador ou expansionista no período eleitoral. As evidências revelaram que os eleitores brasileiros têm preferência por prefeitos que aumentam os gastos públicos nos períodos eleitorais.

Veloso e Bornhold (2016) investigaram o comportamento dos gastos públicos de municípios do Rio Grande do Sul, de maneira a evidenciar que no caso dos chefes do Executivo, o ano eleitoral influência positivamente em determinados gastos. Ainda no contexto dos municípios do Rio Grande do Sul, Nunes (2017) analisou a influência do ano eleitoral nas despesas em educação e 
saúde, sendo que os achados demonstraram não haver aumento dos gastos públicos nos anos de eleição, mas sim uma possível recomposição destas despesas.

Por sua vez, o estudo de Bartoluzzio e Anjos (2020) investigou como os incentivos políticos eleitoreiros influenciam na gestão fiscal dos municípios brasileiros, bem como isso reflete nos resultados eleitorais. Os achados apontaram que existem melhores condições fiscais nos anos eleitorais, porém essa situação se inverte para o ano conseguinte. Os autores constataram, ainda, a presença dos ciclos políticos para a amostra em questão.

Apoiando-se na revisão da literatura descrita nesta seção, a qual denota evidências das relações do período do mandato no aumento dos gastos públicos, foi formulada a hipótese descrita na sequência.

H1: Existem diferenças significativas nos gastos públicos dos senadores em função destes estarem nos primeiros anos ou últimos anos do mandato.

\section{METODOLOGIA}

O estudo se caracteriza como descritivo, com abordagem quantitativa do problema, e busca analisar se há diferenças significativas, no sentido estatístico, nos gastos públicos dos Senadores entre o primeiro e último ano de mandato. Apresenta-se a amostra da pesquisa com 78 senadores, dividida em dois grupos: mandato um são os senadores da legislatura 2011-2018, 2/3 do total (52), e o mandato dois são os da legislatura 2015-2022, 1/3 do total (26).

A coleta de dados refere-se aos gastos com cotas para o exercício da atividade parlamentar dos senadores nos anos de 2016 a 2018, realizada pelo acesso ao Portal da Transparência e tabulada em planilha eletrônica. Desse modo, foram analisados os gastos de aluguel; aquisição; locomoção; contratação; divulgação; passagens e serviços, cujos 7 gastos constam na Cota para o Exercício da Atividade Parlamentar dos Senadores (CEAPS) (Peter \& Machado, 2008).

A questão de grupos ativos no senado traduz o foco de interesse da pesquisa e o fio condutor do trabalho: investigar, conforme os gastos nas CEAPS, no último triênio, se há diferenças significativas nos gastos públicos em relação ao período do mandato em que se encontram. A escolha de serem estudados os anos de 2016, 2017 e 2018 deve-se ao fato de ser o triênio mais recente em relação ao período de coleta de dados. Esta escolha não interfere na qualidade do estudo, tampouco exige a ponderação das demais características devido à heterogeneidade dos fatores.

Ademais, tratando-se da característica regional, Pereira e Rennó (2001) descobriram que fazer parte da mesma coligação do governador do Estado não ajuda o candidato a se reeleger. Tratando-se de possíveis interferências, Soares (2007) apontou a influência limitada dos governadores na eleição para deputado federal, desqualificando-os, portanto, como "locomotivas" das eleições parlamentares. Deposato (2004) chegou à conclusão que o comportamento dos legisladores precisa ser explicado por atores nacionais, sugerindo, por sua vez, que o sistema partidário se estabilizou e, também, que os legisladores estão imunizados contra as influências oriundas das regiões (Estados).

Após tabulação de todos os gastos, os dados foram inflacionados, consonantes ao índice de inflação do mês de dezembro de 2016, nos dados alusivos à 2017 e 2018, com o objetivo de todos os valores estarem equiparados quanto ao poder monetário, a fim de que os resultados estatísticos não fossem distorcidos pelo efeito da valorização monetária. O índice da inflação fora calculado tendo como fonte o Instituto de Pesquisa Econômica Aplicada - Ipeadata.

Para a análise dos dados foi utilizado o software estatístico SPSS 25 para averiguar as relações entre o mandato eleitoral e os gastos públicos. Foram realizadas análises descritivas, correlações de Pearson e Parciais, o Teste de Levene e o Teste da estatística T para duas amostras independentes (Teste de Médias). 
A justificativa para o uso de tais técnicas consiste na essência do objetivo proposto, de forma a permear a análise de valores médios de gastos pelos senadores (Análises Descritivas), a possível existência de correlação entre os gastos dos senados quando segregados por primeiro ou último mandato (Correlações de Pearson e Parciais), bem como a possível diferença entre as médias de gastos, conforme o mandato dos senadores (Teste de Levene e de Médias). Desta forma, por meio das técnicas supracitadas, almeja-se realizar as análises necessárias para cumprimento do objetivo proposto.

\section{ANÁLISE E INTERPRETAÇÃO DOS RESULTADOS}

A presente seção segrega-se em dois momentos. O primeiro corresponde à conjugação da estatística descritiva, sob a ótica basilar da média de gastos por senador. Na segunda são apresentadas as correlações entre os gastos e o teste de médias, no intuito de verificar possíveis diferenças provenientes do mandato em que os senadores se encontram.

Após a tabulação de todos os gastos individuais dos senadores, houve o somatório dos gastos por cota e aplicou-se a média descritiva (Tabela 1), no intento de fornecer a estatística descritiva sobre a média de gastos anuais por cota, segregados em função de estarem exercendo o primeiro ou segundo mandato.

Tabela 1- Média de Gastos por senador (R\$)

\begin{tabular}{|c|c|c|c|c|c|c|}
\hline \multirow{2}{*}{ Gastos } & \multicolumn{3}{|c|}{ Mandato 1} & \multicolumn{3}{|c|}{ Mandato 2} \\
\hline & 2016 & 2017 & 2018 & 2016 & 2017 & 2018 \\
\hline Aluguel & $62.460,10$ & $62.941,76$ & $58.688,41$ & $56.566,30$ & $65.704,42$ & $64.033,59$ \\
\hline Aquisição & $14.370,98$ & $11.179,00$ & $11.754,73$ & $11.076,66$ & $11.014,69$ & $10.246,78$ \\
\hline Locomoção & $80.393,78$ & $77.698,01$ & $70.207,33$ & $71.160,87$ & $66.959,67$ & $61.527,73$ \\
\hline Contratação & $34.368,98$ & $53.362,96$ & $68.148,53$ & $53.270,04$ & $50.653,76$ & $44.291,72$ \\
\hline Divulgação & $46.492,17$ & $52.219,47$ & $28.569,23$ & $43.478,02$ & $40.304,34$ & $26.197,17$ \\
\hline Passagens & $78.663,05$ & $87.596,85$ & $77.787,51$ & $77.655,77$ & $86.416,01$ & $76.940,00$ \\
\hline Serviços & $1.501,44$ & $1.624,85$ & $1.429,85$ & $17.243,01$ & $15.570,31$ & $3.763,90$ \\
\hline Subtotal & $318.250,49$ & $346.622,91$ & $316.585,58$ & $330.450,67$ & $336.623,20$ & $287.000,89$ \\
\hline Total & \multicolumn{3}{|c|}{$981.458,98$} & \multicolumn{3}{|c|}{$954.074,76$} \\
\hline
\end{tabular}

Fonte: Dados da Pesquisa

Por meio dos numerários observados na Tabela 1, observa-se que os senadores que gozam do primeiro mandato eleitoral tiveram gastos totais superiores aos que se encontram no segundo mandato. Tal achado pode demonstrar que os governantes têm a intenção de agradar os eleitores, ao propor ações e executar planejamento nos últimos anos de mandato para se aproximarem da reeleição (Martins \& Correia, 2015).

Ao tornar a análise minuciosa, observando-se os subtotais de gastos por anos, percebe-se que em 2016 os senadores que compunham o segundo mandato apresentaram maiores dispêndios. No entanto, em 2017, ocorreu o inverso, ou seja, os senadores do primeiro mandato incorreram em gastos mais elevados. Partindo do pressuposto que em 2018 ocorreu eleição para senadores, este achado torna-se condizente com Queiroz et al. (2019), uma vez que políticos aptos à reeleição tendem a efetivarem gastos mais elevados, principalmente nos períodos próximos a eleição.

Doravante a alocação da discussão descritiva do comportamento de gastos, prossegue-se para a análise de correlação entre os mesmos. De forma a extrair as especificidades das características que compõe os gastos dos senadores, foram elaboradas correlações para os gastos do primeiro mandato (Tabela 2), segundo mandato (Tabela 3) e gerais (Tabela 4), esta controlada por mandato. 
Tabela 2 - Matriz de Correlação de Pearson, Mandato 1

\begin{tabular}{|c|c|c|c|c|c|c|c|c|c|}
\hline Gastos & Aluguel & Aquisição & Locomoção & Contratação & Divulgação & Passagens & Serviços & Subtotal & Total \\
\hline Aluguel & 1 & & & & & & & & \\
\hline Aquisição & $0.27^{*}$ & 1 & & & & & & & \\
\hline Locomoção & -0.12 & 0.08 & 1 & & & & & & \\
\hline Contratação & -0.09 & 0.02 & $-0.20^{* *}$ & 1 & & & & & \\
\hline Divulgação & $-0.29^{*}$ & $-0.13^{* * *}$ & -0.05 & 0.02 & 1 & & & & \\
\hline Passagens & 0.08 & 0.01 & 0.04 & -0.03 & -0.05 & 1 & & & \\
\hline Serviços & -0.09 & 0.03 & 0.07 & -0.01 & -0.07 & -0.01 & 1 & & \\
\hline Subtotal & $0.15^{* * *}$ & $0.25^{*}$ & $0.44^{*}$ & $0.39 *$ & $0.35^{*}$ & $0.50^{*}$ & 0.03 & 1 & \\
\hline Total & 0.12 & $0.25^{*}$ & $0.45^{*}$ & $0.27^{*}$ & $0.31^{*}$ & $0.48^{*}$ & 0.00 & $0.90^{*}$ & 1 \\
\hline
\end{tabular}

Fonte: Dados da pesquisa.

Legenda: ${ }^{*} \operatorname{Sig}<0.01 ;{ }^{* *} \operatorname{Sig}<0.05 ;{ }^{* *} \operatorname{Sig} \leq 0.10$.

Diversas foram as correlações encontradas no que tange aos gastos efetuados pelos senadores que estão em seu primeiro mandato. Em especial, gastos com divulgação se correlacionam negativamente com gastos de aluguel e aquisição, dispêndios com contratação correlacionam-se de forma negativa com gastos de locomoção, dispêndios com aluguel possuem correlação positiva com gastos de aquisição, enquanto gastos com passagem e serviços não possuem correlações significativas com nenhum outro gasto.

Em relação ao subtotal de gastos por ano, bem como o gasto total, apenas os gastos com serviços não apresentaram correlação significativa com estes. Em específico ao gasto total dos senadores do primeiro mandato, os gastos com aluguéis também não se correlacionam. Na sequência, dispõe-se a Tabela 3, com a matriz de correlações para os gastos dos senadores que perpetuam o segundo mandato.

Tabela 3 - Matriz de Correlação de Pearson, Mandato 2

\begin{tabular}{|c|c|c|c|c|c|c|c|c|c|}
\hline Gastos & Aluguel & Aquisição & Locomoção & Contrataçãa & oDivulgação & Passagens & Serviços & Subtotal & Total \\
\hline Aluguel & 1 & & & & & & & & \\
\hline Aquisição & $0.38^{*}$ & 1 & & & & & & & \\
\hline Locomoção & 0.16 & -0.06 & 1 & & & & & & \\
\hline Contratação & $-0.30^{*}$ & -0.18 & $-0.26^{* *}$ & 1 & & & & & \\
\hline Divulgação & -0.17 & -0.11 & 0.16 & -0.01 & 1 & & & & \\
\hline Passagens & $0.30^{*}$ & 0.11 & $0.23^{* *}$ & -0.17 & -0.01 & 1 & & & \\
\hline Serviços & $-0.22^{* * *}$ & -0.14 & $-0.18^{* * *}$ & 0.09 & 0.03 & $-0.31^{*}$ & 1 & & \\
\hline Subtotal & $-0.24^{* *}$ & 0.05 & $0.47^{*}$ & $0.32^{*}$ & $0.48^{*}$ & $0.38^{*}$ & $0.18^{* * *}$ & 1 & \\
\hline Total & $0.20^{* * *}$ & 0.06 & $0.44^{*}$ & $0.28^{* *}$ & $0.41^{*}$ & $0.31^{*}$ & $0.20^{* * *}$ & $0.89^{*}$ & 1 \\
\hline
\end{tabular}

Fonte: Dados da pesquisa.

Legenda: ${ }^{*} \operatorname{Sig}<0.01 ;{ }^{* *} \operatorname{Sig}<0.05 ;{ }^{* *} \operatorname{Sig} \leq 0.10$.

Referente à Tabela 3, denota-se que apenas os gastos com aquisição não se correlacionam com os subtotais e total, bem como com nenhum outro gasto. Ademais, o aluguel se correlaciona positivamente com a aquisição de passagens e negativamente com contratação e serviços; a locomoção correlaciona-se negativamente com contratações e serviços; e serviços possuem correlação negativa com os gastos relativos a passagens.

Em consonância às correlações evidenciadas para os gastos dos senadores em cada mandato, foram observadas várias diferenças, principalmente nos dispêndios com aluguel, o qual possui correlação significante com outros gastos, principalmente no âmbito do segundo mandato. Por sua vez, os gastos com aquisição são correlacionados aos demais prioritariamente no primeiro mandato. No demais, o segundo mandato apresenta mais correlações entre os dispêndios, de forma geral.

Neste panorama, verificam-se as modificações na composição dos gastos públicos em itens mais visíveis, como serviços (os quais foram maiores para os senadores do segundo mandato), bem como se correlacionam negativamente com demais gastos (que diminuíram nos senadores do 
primeiro para o segundo mandato) em relação ao gasto com investimentos, no qual os resultados exigem mais tempo para serem percebidos pelo eleitorado (Rogoff, 1990; Rogoff \& Sibert, 1988).

Após a análise individual da correlação dos gastos por mandato, por meio de correlações parciais, promove-se o controle por mandato (Tabela 4), no intento de analisar o comportamento correlacionado dos gastos globais, tendo por variável de controle o período de mandato em que o senador se encontra.

Tabela 4 - Matriz de Correlação Parcial, Controlada por Mandato

\begin{tabular}{|c|c|c|c|c|c|c|c|c|c|}
\hline Gastos & Aluguel & Aquisição & Locomoção & Contratação & Divulgação & Passagens & Serviços & Subtotal & Total \\
\hline Aluguel & 1 & & & & & & & & \\
\hline Aquisição & $0.31^{*}$ & 1 & & & & & & & \\
\hline Locomoção & -0.04 & 0.04 & 1 & & & & & & \\
\hline Contratação & $-0.17^{*}$ & -0.04 & $-0.22^{*}$ & 1 & & & & & \\
\hline Divulgação & $-0.25^{*}$ & $-0.12^{* * *}$ & 0.01 & 0.01 & 1 & & & & \\
\hline Passagens & $0.15^{* *}$ & 0.03 & 0.09 & -0.08 & -0.03 & 1 & & & \\
\hline Serviços & $-0.14^{* *}$ & -0.06 & -0.08 & 0.05 & 0.01 & $-0.15^{* *}$ & 1 & & \\
\hline Subtotal & $0.18^{*}$ & $0.19^{*}$ & $0.45^{*}$ & $0.36^{*}$ & $0.39^{*}$ & $0.46^{*}$ & $0.11^{* * *}$ & 1 & \\
\hline Total & $0.15^{* *}$ & $0.19^{*}$ & $.045^{*}$ & $0.28^{*}$ & $0.34^{*}$ & $0.43^{*}$ & $0.11^{* * *}$ & $0.90^{*}$ & 1 \\
\hline
\end{tabular}

Fonte: Dados da pesquisa.

Legenda: ${ }^{*} \operatorname{Sig}<0.01 ; *$ Sig $<0.05 ; * * \operatorname{Sig} \leq 0.10$.

Por meio do controle por mandato nos gastos dos senadores, percebe-se, de forma global, que todos os dispêndios se correlacionam positivamente com os gastos subtotais e totais, como esperado. Nesta análise de correlação percebe-se que o aluguel apenas não se correlaciona com locomoção; a aquisição, locomoção e divulgação seguem a lógica do que fora evidenciado no mandato 1 (Tabela 2); a contratação segue o padrão encontrado no Mandato 2 (Tabela 3); passagens e serviços correlacionam-se diferentemente em todas três matrizes de correlação.

Destarte as análises de correlação, parte-se para a análise de igualdade (ou não) das variâncias assumidas. Para tal, utiliza-se do Teste de Levene (Tabela 5), para verificação da homogeneidade das variâncias, que se torna um pertinente pressuposto na análise do Teste $\mathrm{T}$ para amostras independentes (Fávero, Belfiore, Silva, \& Chan, 2009).

Tabela 5 - Teste de Levene para Igualdade de Variâncias

\begin{tabular}{lccc}
\hline Gastos & $\mathbf{Z}$ & Significância & Variâncias Iguais Assumidas \\
\hline Aluguel & 2.10 & 0.14 & Sim \\
Aquisição & 0.28 & 0.59 & Sim \\
Locomoção & 2.47 & 0.11 & Sim \\
Contratação & 1.62 & 0.20 & Sim \\
Divulgação & 1.22 & 0.27 & Sim \\
Passagens & 0.17 & 0.89 & Sim \\
Serviços & 0.01 & 0.95 & Sim \\
Subtotal & 0.27 & 0.60 & Sim \\
Total & 0.45 & 0.50 & Sim \\
\hline
\end{tabular}

Fonte: Dados da pesquisa.

Nota: Os valores das variáveis foram convertidos em seu logaritmo natural.

Partindo do pressuposto de variâncias iguais assumidas, visto da não significância estatística de $\mathrm{Z}$, prossegue-se para o Teste $\mathrm{T}$ para duas amostras independentes, no caso em questão, o primeiro e o segundo mandato dos senadores (Tabela 6). 
Tabela 6 - Teste T para duas amostras independentes

\begin{tabular}{|c|c|c|c|c|c|c|c|c|}
\hline \multirow{2}{*}{ Gastos } & \multicolumn{3}{|c|}{ Primeiro Mandato } & \multicolumn{3}{|c|}{ Segundo Mandato } & \multirow{2}{*}{ Teste $\mathrm{T}$} & \multirow{2}{*}{ Valor $p$} \\
\hline & $\mathrm{N}$ & Média & DP & $\mathrm{N}$ & Média & DP & & \\
\hline Aluguel & 143 & 10.88 & 0.79 & 65 & 11.06 & 0.60 & -1.61 & $0.10^{* * *}$ \\
\hline Aquisição & 110 & 9.08 & 1.38 & 51 & 9.07 & 1.30 & 0.05 & 0.95 \\
\hline Locomoção & 139 & 10.83 & 1.39 & 69 & 10.56 & 1.61 & 1.24 & 0.21 \\
\hline Contratação & 130 & 10.14 & 1.80 & 59 & 10.27 & 1.57 & -0.49 & 0.62 \\
\hline Divulgação & 114 & 9.93 & 1.87 & 50 & 10.12 & 1.64 & -0.61 & 0.53 \\
\hline Passagens & 143 & 11.14 & 0.90 & 75 & 11.13 & 0.75 & 0.10 & 0.92 \\
\hline Serviços & 21 & 7.72 & 2.08 & 17 & 9.02 & 2.12 & -1.89 & $0.06^{* * *}$ \\
\hline Subtotal & 156 & 12.58 & 0.60 & 78 & 12.53 & 0.70 & 0.54 & 0.58 \\
\hline Total & 156 & 13.71 & 0.46 & 78 & 13.69 & 0.41 & 0.34 & 0.72 \\
\hline
\end{tabular}

Fonte: Dados da Pesquisa.

Legenda: N = População; DP = Desvio Padrão; ${ }^{* *}$ Sig $\leq 0.10$.

Nota: Os valores das variáveis foram convertidos em seu logaritmo natural.

Por meio do teste de médias entre os gastos dos senadores que estão nos últimos anos do mandato e dos senadores que estão nos primeiros anos de mandato, pode-se inferir estatisticamente, ao nível de significância de $10 \%$, que existem diferenças significativas no que tange aos dispêndios com aluguel e serviços, sendo ambos superiores para o grupo de senadores que exercem os primeiros anos de mandato. Assim não se pode rejeitar $\mathrm{H}_{1}$ a um nível de significância de $10 \%$, indicando que o período do mandato dos senadores influencia a diferença nos gastos públicos.

Os resultados obtidos corroboram com o estudo Queiroz et al. (2019) que mostraram que o comportamento oportunista é restrito aos governadores que estão nos primeiros anos de mandato na composição dos gastos públicos em direção aos investimentos e a execução dos planejamentos. De forma similar, Queiroz, Nobre, Da Silva e Araújo (2013) identificaram um aumento dos gastos públicos em direção aos investimentos nos anos eleitorais dos gestores que estão nos primeiros anos de mandato.

Na pesquisa de Klein e Sakurai (2015), que propuseram estudar o mandato eleitoral como um fator determinante para a ocorrência dos ciclos político-orçamentários, os resultados mostraram que os prefeitos que estão no primeiro mandato aumentaram a despesa pública, especialmente os investimentos. Essas evidências revelam que, tanto no nível municipal quanto no federal, existe aumento nos gastos públicos nos anos eleitorais, de forma mais significativa nos governos cujos gestores estão nos primeiros anos do mandato em relação aos que estão em últimos anos mandato.

O estudo de Neto, Gomes e Ervilha (2018) aponta que os parlamentares nos últimos anos do mandato, prováveis candidatos à reeleição, podem estar maximizando seus gastos públicos e atuação pública, visando conquistar sucesso no resultado eleitoral. Desse modo, as modificações na composição dos gastos públicos são em itens mais visíveis, como serviços, diminuindo-se o gasto com investimentos, cujos resultados exigem mais tempo para serem percebidos pelo eleitorado (Rogoff, 1990; Rogoff \& Sibert, 1988).

\section{CONSIDERAÇÕES FINAIS}

A presente investigação teve como objetivo analisar se existem diferenças significativas nos gastos públicos dos senadores que se encontram no primeiro e no segundo mandato eleitoral. Para tanto, foram analisados gastos públicos de 78 senadores, sendo 52 exercendo o primeiro mandato e 26 o segundo mandato, com dados correspondentes aos anos de 2016 a 2018.

Constata-se maior média de gastos públicos dentre o grupo de senadores que exercem o primeiro mandato em relação com os que estão com o segundo mandato. Os achados apontam indícios que existem diferenças significativas nos gastos públicos com aluguel e serviços, sendo 
numerários superiores para os senadores que estão exercendo o segundo mandato. Ainda, o aluguel mantém maior correlação com os demais gastos, quando comparado aos serviços.

O estudo conclui que, de maneira geral, a maior parte dos gastos públicos analisados não demonstra diferença significativa em relação ao mandato em que os senadores estão exercendo. Apesar dos senadores que exercem o primeiro mandato apresentarem maior média geral de gastos para aluguel e serviços, estes dois gastos são significativamente maiores para os senadores que atuam no segundo mandato.

Tal achado demonstra-se pertinente, uma vez que estes dois gastos (aluguel e serviços), ao contrário dos demais, não estão diretamente ligados com uma possível reeleição (Ex.: Divulgação, passagens e locomoção). Por meio destes resultados, pode-se inferir que os senadores que estão no primeiro mandato possuem gastos mais elevados relacionados à promoção de uma possível reeleição, enquanto os senadores que estão no segundo mandato possuem maiores gastos com serviços benéficos a eles próprios (ex.: aluguel).

No âmbito de implicações teóricas, o estudo contribui com a literatura sobre ciclos políticos, abarcando os gastos públicos com senadores brasileiros, em específico ao analisar a diferença de gastos em relação aos senadores que estão no primeiro ou segundo mandato. $O$ estudo estende a discussão de ciclos políticos no cenário nacional, além de focar no Senado Federal, o que escassos estudos fazem.

Sob a ótica de implicações práticas, a pesquisa espera instigar o acompanhamento social da aplicação dos recursos públicos, em especial aos gastos executados por políticos, e em específico, senadores. Além disso, proporciona o direito do cidadão quanto ao acompanhamento da destinação de recursos públicos, que se configura como exercício da cidadania, fato que reforça a necessidade de fiscalização e participação dos indivíduos no que tange aos assuntos políticos.

A pesquisa apresenta algumas limitações, como a delimitação temporal, ao abranger apenas três anos, bem como não promover o controle e análises por partido, posição ideológica, unidade federativa, dentre outras variáveis. A partir destes fatores limitantes, surgem novas oportunidades de pesquisa, as quais podem se concentrar, além do Senado Federal, na Câmara dos Deputados.

\section{REFERÊNCIAS}

Alt, J. E., \& Lassen, D. D. (2006). Transparency, political polarization, and political budget cycles in OECD countries. American Journal of Political Science, 50(3), 530-550.

Andrade, N. D. A. (2012). Contabilidade pública na gestão municipal: métodos com base nas normas brasileiras de contabilidade aplicadas ao setor público (NBCASP) e nos padrões internacionais de contabilidade. São Paulo: Atlas.

Araújo, J. A., Cavalcante, C. A. \& Monteiro, V. B. (2010). Influência dos Gastos Públicos no Crescimento Econômico dos Municípios do Ceará. In: Anais $6^{\circ}$ Economia do Ceará em Debate (pp.176200). Fortaleza, CE, Brasil.

Araújo, J. F. F. E. D., \& Tejedo-Romero, F. (2016). Local government transparency index: determinants of municipalities' rankings. International Journal of Public Sector Management, 29(4), 327347. doi.org/10.1108/IJPSM-11-2015-0199

Arvate, P. R., Mendes, M., \& Rocha, A. (2010). Are Voters Fiscal Conservatives? Evidence from Brazilian Municipal Elections. Estudos Econômicos, 40(1), 67-101. doi.org/10.1590/S010141612010000100003

Bartoluzzio, A. I. S. D. S., \& Anjos, L. C. M. D. (2020). Ciclos Políticos e Gestão Fiscal nos Municípios Brasileiros. Revista de Administração Contemporânea, 24(2), 167-180. doi.org/10.1590/19827849rac2020190190 
Brender, A., \& Drazen, A. (2005). Political budget cycles in new versus established democracies. Journal of Monetary Economics, 52(7), 1271-1295. doi.org/10.1016/j.jmoneco.2005.04.004

Brender, A., \& Drazen, A. (2013). Elections, leaders, and the composition of government spending. Journal of Public Economics, 97(1), 18-31. doi.org/10.1016/j.jpubeco.2012.08.011

Carvalho, F. A. A., \& Oliveira, K. V. (2009). A contabilidade governamental e a teoria dos ciclos políticos: uma análise empírica fiscal e contábil sobre os municípios do estado do Rio de Janeiro - 1998/2006. Revista de Educação e Pesquisa em Contabilidade, 3(1), 46-64. doi.org/10.17524/repec.v3i1.40

Cruz, N. F., Tavares, A. F., Marques, R. C., Jorge, S., \& De Sousa, L. (2016). Measuring local government transparency. Public Management Review, 18(6), 866-893. doi.org/10.1080/14719037.2015.1051572

Desposato, S. (2004). The impact of federalism on national party cohesion in Brazil. Legislative Studies Quarterly, 29(2), 259-285.

Downs, A. (1957). An economic theory of political action in a democracy. Journal of political econo$m y, 65(2), 135-150$.

Drazen, A. (2001). The political business cycle after 25 years. NBER Macroeconomics Annual, 15(1), 75-138. doi.org/10.2307/3585387

Drazen, A., \& Eslava, M. (2010). Electoral manipulation via voter-friendly spending: theory and evidence. Journal of Development Economics, 92(1), 39-52. doi.org/10.1016/j.jdeveco.2009.01.001

Fávero, L. P., Belfiore, P., Silva, F. L., \& Chan, B. L. (2009). Análise de dados: modelagem multivariada para tomada de decisões. Rio de Janeiro: Elsevier.

Ferreira, T. S. (2016). Receitas e despesas públicas: Enfoque Patrimonial X Enfoque Orçamentário. Revista de Administração e Contabilidade da FAT, 8(1), 27-39.

Fiirst, C., Santos, A. C. dos, Rodrigues Junior, M. M., \& Zonatto, V. C. da S. (2019). Características políticas e desempenho financeiro público sob a luz da teoria dos ciclos políticos. Contextus: Revista Contemporânea de economia e gestão, 17(1), 127-144. doi.org/ 10.19094/contextus.v17i1.33608

Grimmelikhuijsen, S. G., \& Welch, E. W. (2012). Developing and testing a theoretical framework for computer-mediated transparency of local governments. Public administration review, 72(4), 562-571. doi.org/10.1111/j.1540-6210.2011.02532.x

Hood, C. (2006). Transparency in historical perspective. New York: Oxford University Press.

Kjaer, A. M. (2004). Governance: key concepts. Cambridge: Cambridge University Press.

Klein, F. A. (2010). Reelection incentives and political budget cycle: evidence from Brazil. Revista de Administração Pública, 44(2), 283-337. doi.org/10.1590/S0034-76122010000200006

Klein, F. A., \& Sakurai, S. N. (2015). Term limits and political budget cycles at the local level: evidence from a young democracy. European Journal of Political Economy, 37(1), 21-36. doi.org/10.1016/j.ejpoleco.2014.10.008

Martins, P., \& Correia, L. (2015). Determinantes dos desvios orçamentais nos municípios portugueses. Revista Portuguesa de Estudos Regionais, 39(3), 41-64.

Meijer, A. (2015). Government transparency in historical perspective: from the ancient regime to open data in the Netherlands. International Journal of Public Administration, 38(3), 189-199. doi.org/10.1080/01900692.2014.934837

Medeiros, S. A., Magalhães, R., \& Pereira, J. R. (2014). Lei de acesso à informação: em busca da transparência e do combate à corrupção. Informação $\mathcal{E}$ informação, 19(1), 55-75. dx.doi.org/10.5433/1981-8920.2014v19n1p55

Nakaguma, M. Y., \& Bender, S. (2010). Ciclos Políticos e Resultados Eleitorais: Um Estudo sobre o Comportamento do Eleitor Brasileiro. Revista Brasileira de Economia, 64(1), 3-24. dx.doi.org/10.1590/S0034-71402010000100001 
Nascimento, R. E. (2006). Gestão Pública: Tributação e Orçamento; Lei de Responsabilidade Fiscal; Tópicos em Contabilidade Pública; Gestão Pública no Brasil, de JK a Lula; Administração Financeira e Orçamentária e Finanças Públicas nos Três Níveis de Governo. Saraiva ( $3^{\mathfrak{a}}$ ed), São Paulo.

Neto, W. P., Gomes, A. P., \& Ervilha, G. T. (2018). Uma análise de eficiência para os senadores brasileiros. Revista de Desenvolvimento e Políticas Públicas, 2(1), 03-20. doi.org/10.31061/redepp.v2n1.03-20

Nordhaus, W. D. (1975). The political business cycle. The review of economic studies, 42(2), 169-190.

Nunes, G. S. (2017). Ciclos políticos orçamentários: uma análise das despesas em educação e saúde para os municípios do Rio Grande do Sul (2002-12). Indicadores Econômicos FEE, 44(4), 99-110.

Pereira, C., \& Rennó, L. (2001). O Que é que o Reeleito Tem? Dinâmicas Político-Institucionais Locais e Nacionais nas Eleições de 1998 para a Câmara dos Deputados. Dados, 44(2), 323-362. doi.org/10.1590/S0011-52582001000200004.

Peter, M. G. A., \& Machado, M. V. V. (2008). Manual de Auditoria Governamental. 1 ed. São Paulo: Atlas.

Queiroz, D. B., Araújo, A. O., De Morais, L. M. F., \& Da Silva, V. K. R. (2015). Composição do Gasto Público e Resultados Eleitorais: Um Estudo nos Municípios Paraibanos no Ano de 2012. Registro Contábil, 6(3), 38-55.

Queiroz, D. B., De Morais, L. M. F., De Souza, A. G. S. F., \& Da Silva, V. K. R. (2019). Mandatos Eleitorais e Ciclos Político-Orçamentários: Evidências dos Estados Brasileiros. Administração Pública e Gestão Social, 11(2), 1-18.

Queiroz, D. B., Nobre, F. C., Da Silva, W. V., \& Araújo, A. O. (2013). Transparência dos Municípios do Rio Grande do Norte: avaliação da relação entre o nível de disclosure, tamanho e características socioeconômicas. Revista Evidenciação Contábil \& Finanças, 1(2), 38-51. doi.org/ $0.18405 /$ recfin20130203

Queiroz, D. B. (2018). Influência do ano eleitoral, da mudança de gestor público e do mandato eleitoral sobre mudanças na composição dos gastos públicos nos estados brasileiros. REUNIR: Revista de Administração, Contabilidade e Sustentabilidade, 8(3), 68-77. doi.org/10.18696/reunir.v8i3.789

Rezende, C, F da. (1997). Descentralização, gastos públicos e preferências alocativas dos governos locais no Brasil (1980 - 1994). Dados, 40(3).

Rogoff, K. (1990). Equilibrium political budget cycles. American Economic Review, 80(1), 21-26.

Rogoff, K., \& Silbert, A. (1988). Elections and macroeconomic policy cycles. Review of Economic Studies, 55(1), 1-16.

Sakurai, S. N. (2009). Ciclos políticos nas funções orçamentárias dos municípios brasileiros: uma análise para o período 1990 - 2005 via dados em painel. Estudos Econômicos, 39(1), 39-58. dx.doi.org/10.1590/S0101-41612009000100002

Sakurai, S. N., \& Menezes-Filho, N. (2008). Fiscal policy and reelection in Brazilian municipalities. Public Choice, 137(1-2), 301-314.

Sakurai, S. N. \& Menezes-Filho, N. A. (2011). Opportunistic and partisan election cycles in Brazil: new evidence at the municipal level. Public Choice, 148(1-2), 233-247.

Scarpin, J. E., \& Slomski, V. (2007). Estudo dos fatores condicionantes do índice de desenvolvimento humano nos municípios do estado do Paraná: instrumento de controladoria para a tomada de decisões na gestão governamental. Revista de Administração Pública-RAP, 41(5), 909-933.

Shepsle, K. A., Van Houweling, R. P., Abrams, S. J., \& Hanson, P. C. (2009). The Senate Electoral Cycle and Bicameral Appropriations Politcs. American Journal of Political Science, 53(2), 343-359.

Silva, L. M. (2004). Contabilidade governamental: um enfoque administrativo. Atlas. 
Slomski, V. (2003). Manual de contabilidade pública: um enfoque na contabilidade municipal, de acordo com a lei de responsabilidade fiscal. (2a ed.) São Paulo: Atlas.

Soares, M. (2007). Democracia, representação política e federalismo no Brasil. Tese de Doutorado, Instituto Universitário de Pesquisas do Rio de Janeiro, Rio de Janeiro, RJ, Brasil.

Souza, F. J. V. D., Araújo, A. O., \& Silva, M. C. D. (2016). Índice de informação contábil pública: um estudo nos municípios brasileiros. Revista Catarinense da Ciência Contábil, 15(44), 37-48. dx.doi.org/10.16930/2237-7662/rccc.v15n44p37-48

Veiga, L. G., \& Veiga, F. J. (2007). Political business cycles at the municipal level. Public Choice, 131(1-2), 45-64.

Veloso, G. de O., \& Bornhold, S. D. (2016). Averiguação empírica de ciclos políticos nos municípios gaúchos, entre 1995 e 2008. Ensaios FEE, 36(4), 1069-1096.

Vicente, E. F. R., \& Nascimento, L. S. (2012). A efetividade dos ciclos políticos nos municípios brasileiros: um enfoque contábil. Revista de Contabilidade e Organizações, 6(14), 106-126. 